Annals of Tropical Research 30(1):72-92(2008)

(c) VSU, Leyte, Philippines

\title{
Effects of the mechanical factors on the peeling of cassava
}

\author{
Jesus G. Sagragao' and Daniel Leslie S. Tan² \\ ${ }^{1}$ Department ofAgricultural Engineering, College of Agri-Industries, Visayas State \\ University, Baybay City, Leyte, Philippines, ${ }^{2}$ Philippine Root Crop Training Center \\ (PhilRootcrops), Visayas State University, Baybay City, Leyte 6521 Philippines
}

\begin{abstract}
This study was conducted to determine the effects of the clearance distance angular speed and direction of rotation of the rollers to the mechanical peeling of cassava. A device consisting of two furrowed rollers with straight corrugations about $2 \mathrm{~mm}$ deep, lever root presser and driving mechanism all attached to the frame was evaluated according to its peeling recovery and degree of peeling at the following factor combinations: clearance distance between rollers at $80 \%$ and $90 \%$ of the diameter of the roots, three angular speed combinations at $175 \times 144 \mathrm{rpm}, 175 \times 180 \mathrm{rpm}$ and $175 \times 405 \mathrm{rpm}$ and directions of rotations (the same and opposite) of the rollers. The Lakan variety of cassava was used in the evaluation. The cassava root with at least uniform diameters of $35 \mathrm{~mm}, 50 \mathrm{~mm}$ and $65 \mathrm{~mm}$ was fed individually, parallel to the axial rotation of the rollers then pressed to the rollers. Results indicated that the efficient peeling of the cassava roots was attained at $175 \times 405 \mathrm{rpm}$ at the $90 \%$ clearance distance of the same direction of rotation of the rollers.
\end{abstract}

Keywords: cassava peeling, mechanical factors, rollers

Correspondence: D. L. S. Tan Address: PhilRootcrops, Visayas State University, Baybay City, Leyte 6521 Philippines Telephone: (053) 335-2616E-mail: dlstan1@yahoo.com.ph DOI: $10.32945 /$ atr3016.2008 


\section{INTRODUCTION}

Cassava (Manihot esculenta Crantz) is a perennial vegetatively propagated shrub that is grown throughout the lowland tropics. It is one of the important food crops in the tropics, especially of the poorer areas, because it has the ability to grow well under near drought conditions (Anantharam, 1993). Grace (1977) reported that cassava roots may reach a size of $30-120 \mathrm{~cm}$ long and $4-15 \mathrm{~cm}$ in diameter and a weight of $1-8 \mathrm{~kg}$ and more.

In the Philippines, cassava locally known as "kamoteng kahoy" or "kalibre" is considered as one of the major crops next to rice and corn. It is produced into many food products like cassava cake, cassava rolls, pitsipitsi, cacharon, bakery products to name a few. These products are made either of cassava flour or cassava grates.

Village level technology in the production of cassava flour and grates is already available. This includes a collection of machine to perform each of the processing operations involved. Peeling operation however is not included and therefore has to be done manually. When processing large volume of cassava, manual peeling may no longer be feasible. Tan et al.,(1996) reported that the manual peeling operation constitutes about $50 \%$ of the total labor cost in the processing of cassava into flour or dried grates. mechanical peeler, therefore, becomes necessary.

The peel, which comprises $10-20 \%$ of the roots, consists of an outer and inner part. The outer comprises a layer of cork cells and the phelloderm. The cork layer represents $0.5-2 \%$ of the total tuber weight (Onwueme and Charles, 1994). The inner part of the peel contains the phelloderm and the phloem, which separate the peel from the body of the root. The texture of the transition layer makes possible an easy loosening of the whole peel from the central part thus facilitating the peeling of the roots.

Diop (1998) reported that in an easy to peel varieties of cassava, peeling is done by slitting along the length of one side of the root while the knife-blade and the fingers are used to rollback the peel from the fleshy portion. In more diffuclt varieties, the two layers of peel are often whittled in a motion reminiscent of sharpening a pencil. However the operation was found to be less satisfactory because it results in the removal of much flesh due to the imperfect removal of peel. 
Peeling as one of the operations in cassava processing in small and medium-size mills, the generally practiced operation is to remove the peel (skin and cortex) and processing only the central part of the root, which is of much softer texture. In small-scale production, peeling is done by rasping away the outer brown and white layer from the root with the use of teeth or knives made of wood or flint. In contrary, for commercial production,peeling is done with the use of mechanical peeler with the waste rises to $25-30 \%$ compared to hand peeling with losses that ranges from $12 \%$ to $15 \%$ (Canzales, 1991).

Nwokedi (1984) and his colleagues in the National Root Crops Research Institute (MRCRI) in Nigeria developed a mechanical peeler reported to be suitable for village use. The machine consists of a $35 \mathrm{~cm}$ diameter oval chamber mounted on two-mild-steel rods with holes cut along the walls and lined with sharp wire gauze. It needs to be carefully adjusted to peel at maximum efficiency to offset the time and labor used in manual operation. The machine performance was best for medium and large roots. The Post-harvest Engineering Unit of IITA of Nigeria developed a very simple manual peeler that can peel up to $30 \mathrm{~kg} / \mathrm{h}$ depending on experience. It targets only households. The peeling tool consists of three main parts: hard rubber peeling blade, cutting blade and the handle. Also in Nigeria, a mechanical peeler that is simple, robust, but a large piece of equipment was developed. It consists of a big drum-like grater that rotates horizontally above an even bigger triangular basin. the unpeeled cassava tubers are feed in succession into the drum where the skins are grated off and the tubers washed. A ton can be processed this way in a few minutes but more than $50 \%$ of the cassava goes to wastes.

In France, a stripper-crusher mechanical peeler that splits cassava roots vertically into four long pieces was developed. The machine however had considerable loss which resulted from an attempt to peel non-uniform cassava quarters since the inner skin cannot be reached.

Odigboh (1976) disclosed that a mechanical device for effective peeling of cassava roots must be capable of peeling the root of all varieties despite variations in physical and mechanical properties. He also reported the factors that affect the peeling of cassava roots are size and shape of the roots, the variability in cassava peel thickness, and the physcial and mechanical properties of the roots which depend on the age of the roots at time of harvest. 
Indeed, it is difficult to make an efficient mechanical peeler for cassava particularly that there is no available information on the peeling characteristics of each variety of cassava. There is therefore a need to establish basic information on the factors affecting the peeling of cassava roots particularly their physical and mechanical properties and the effect of mechanical forces (shearing and compression).

This study principally tried to establish information on the mechanical factors affecting the peeling of cassava roots. Specifically, it aimed to determine the effect of the clearance between rollers on the peeling of cassava, determine the effect of angular speed of the roller on the peeling of cassava, and determine the effect of the direction of rotation of the rollers on the peeling of cassava roots.

\section{MATERIALS AND METHODS}

\section{The experimental set-up}

Figure 1 shows the schematic diagram of the cassava peeling machine used in this study. It consists of two cylindrical rollers; one is fixed while the other is movable, mounted parallel on a frame at an adjustable clearance distance apart. Its driving mechanism was composed of the chains and sprockets connecting the motor and the rollers. The lever root presser attached to the frame was made of wood and used to provide pressure on the cassava roots.

\section{Tuber preparation}

The Lakan variety of cassava was used in the experiment. The cassava roots were harvested from the experimental plot of PhilRootcrops. They were then washed, cut into $100 \mathrm{~mm}$ in length of at least uniform diameter and weighed. 


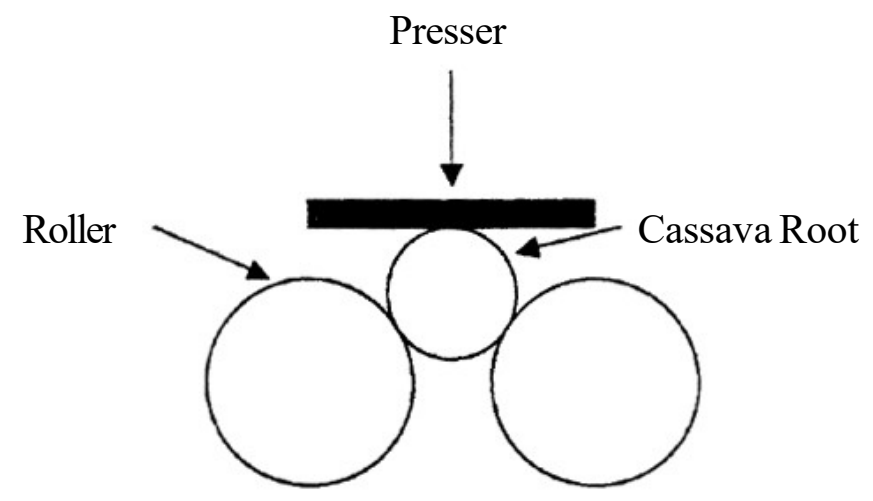

Figure 1. Schematic diagram of the cassava peeling mechanism 


\section{The peeling operation}

A 1-hp motor, rated at $1750 \mathrm{rpm}$ was used to drive the rollers of the experimental set-up. The cassava root was fed individually parallel to the axial rotation of the two rollers. The lever root presser attached to the frame pressed the root. The root was forced to pass through between the two rollers. The peeled root was visually evaluated and weighed.

\section{Experimental design and treatment}

The experimental set-up was evaluated at three replications with clearance distance, angular speed and direction of rotation of the rollers as factors at three ranges of cassava root diameter.

\section{Percent clearance}

It is referred to as the percent of the ratio of the distance between the two rollers and the diameter of the cassava root. It can be computed from the equation below:

$$
\% \text { Clearance }=\frac{\mathrm{D}_{\mathrm{C}}}{\mathrm{D}_{\mathrm{R}}}
$$

where: $\mathrm{D}_{\mathrm{C}}=$ Clearance distance between rollers $\mathrm{D}_{\mathrm{R}}=$ Root diameter

In this study, percent clearance used were $80 \%$ and $90 \%$, respectively.

\section{Angular Speed} formula:

The angular speed combinations of the rollers were computed from the

$$
\mathrm{N}_{\mathrm{o}} \mathrm{T}_{\mathrm{o}}=\mathrm{N}_{\mathrm{n}} \mathrm{T}_{\mathrm{n}}
$$

where: $\mathrm{N}_{\mathrm{o}}=$ Angular speed of the fixed roller, $\mathrm{rpm}$

$\mathrm{N}_{\mathrm{n}}=$ Angular speed of the movable roller, rpm

$\mathrm{T}_{\mathrm{o}}=$ Number of teeth of the fixed sprocket 
$\mathrm{T}_{\mathrm{n}}=$ Number of teeth of the variable sprocket

The change in speed combinations were done by changing the number of the variable sprocket mounted at the movable roller.

\section{Diameter of rotation}

The two rollers were subjected to two directions of rotation: $\mathrm{R}_{1}$, where the two rollers were to operate at the same counterclockwise direction; and $\mathrm{R}_{2}$ where the two rollers were to rotate at opposite direction ( the fixed roller was in counterclockwise while the other was in clockwise direction of rotation, respectively), with respect to the front of the machine.

\section{Diameter of the root}

The following were the ranges of root diameter used:

$\mathrm{D}_{1}=35 \mathrm{~mm}+5 \mathrm{~mm}$

$\mathrm{D}_{2}=50 \mathrm{~mm} \pm 5 \mathrm{~mm}$

$\mathrm{D}_{3}=65 \mathrm{~mm} \pm 5 \mathrm{~mm}$

The range used was based on the available cassava tubers of uniform diameter.

Amount of peel

The amount of peels removed from the root was quantified using the range of the removal of the peels as follows:

Peeled $=$ when $100 \%$ of the peels were removed

Half peeled $=$ when $50 \%$ of the peels were removed

Partially peeled $=$ when only $25 \%$ of the peels were removed

Furthermore, the condition of which the cassava root has passed through between the rollers was also noted. 


\section{Data gathered}

The following were the data collected:

a. Weight of the cassava root before peeling $\left(\mathrm{W}_{\mathrm{b}}\right)$

b. Weight of the cassava root after peeling $\left(\mathrm{W}_{\mathrm{a}}\right)$

c. Amount of peels removed $\left(\mathrm{W}_{\mathrm{p}}\right)$

d. Diameter of the roots before peeling $\left(D_{b}\right)$

\section{Peeling evaluation}

The degree of peeling which refers to the removal of the peels alone approximately quantified based on the maount of peels removed from the cassava roots after peeling.

Analysis of data

Data gathered were analyzed using the Randomized Complete Block Design (RCBD) following the analysis of variance (ANOVA) table.

Further test of significance of treatment means was done using the Duncan's Multiple Range Test (DMRT).

\section{RESULTS AND DISCUSSION}

\section{Development of the experimental set-up}

The experimental set-up was developed to determine the effects of the mechanical forces (combined compression and shearing) on the peeling of the cassava roots. The roots were subjected to the following factors: three combinations of angular speed, two directions of rotation, and two clearance distances of the rollers at three ranges of root diameters.

The action of forces acting on the cassava root at two direction of rotation is illustrated in Figure 2; where $\mathrm{F}_{\mathrm{c}}$ is the compressive force exerted by the root presser to the root; $\mathrm{F}_{\mathrm{a} 1}$ and $\mathrm{F}_{\mathrm{b} 4}$ are the shear forces exerted by the rollers 


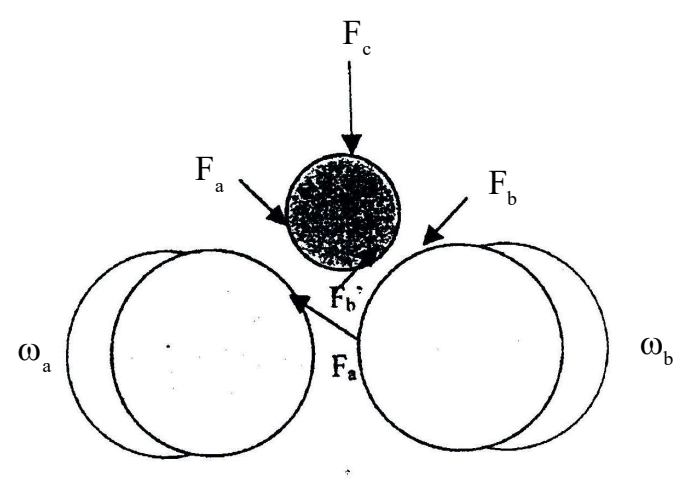

a. The same direction

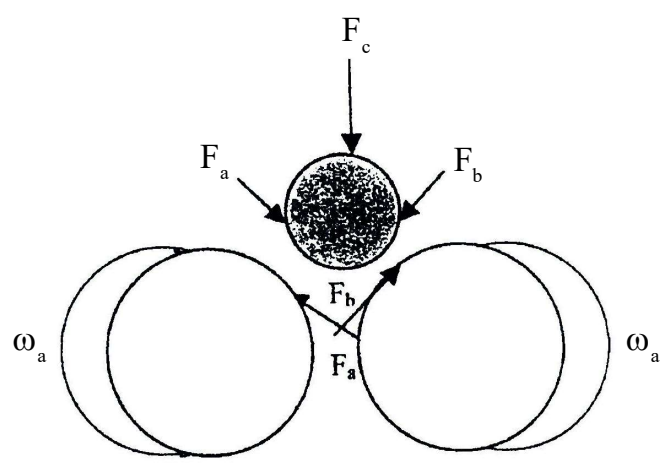

a. The opposite direction

Figure 2. Compression and shearing forces acting on the root: (a) the same and (b) opposite directions of rotation of the rollers 
(fixed and movable) to the root and $\mathrm{F}_{\mathrm{a} 2}$ and $\mathrm{F}_{\mathrm{b} 2}$ are the reaction forces of the roots, and $\omega_{\mathrm{a}}$ and $\omega_{\mathrm{b}}$ are the angular speed of the rollers, respectively.

\section{Description of the experimental set-up}

The experimental set-up, which is a machine, is composed of four main parts: the frame, the rollers, the lever root presser and the power transmission assembly (Figure 3a).

\section{Frame}

The frame holds the rollers, the root presser and the driving mechanism of the experimental set-up. It is constructed from $\left(1 \frac{1 / 2}{2} \mathrm{X}^{3 /,}{ }_{16}\right.$ ) angle bar, cut and welded into the required lengths as shown in the working drawings. Holes of $9.5 \mathrm{~mm}\left(3 / 8^{\prime \prime}\right)$ in diameter were drilled for mounting the pillow block bearings, motor and speed reducer in their proper places. Slotted holes of 9.5 x 100 $\mathrm{mm}$ were also made for mounting the pillow block bearings for the movable roller and the idler sprocket.

\section{Rollers}

The rollers were furrowed of straight parallel corrugation on the surface, spaced at about $2 \mathrm{~mm}$ of a depth of $2 \mathrm{~mm}$. The rollers were of $15 \mathrm{~cm}$ in diameter and of $31.5 \mathrm{~cm}$ in length.

\section{Lever-root presser}

The assembly of the root presser was made of scrap materials. Its handle was made of a GI pipe hinged at the opposite end. The presser was made of wood attached to the angle bar to the handle.

\section{Power transmission assembly}

The transmission assembly was composed of a 1-Hp, $1750 \mathrm{rpm}$, and single-phase electric motor and a 1:10 speed reducer. The rpm of the motor 


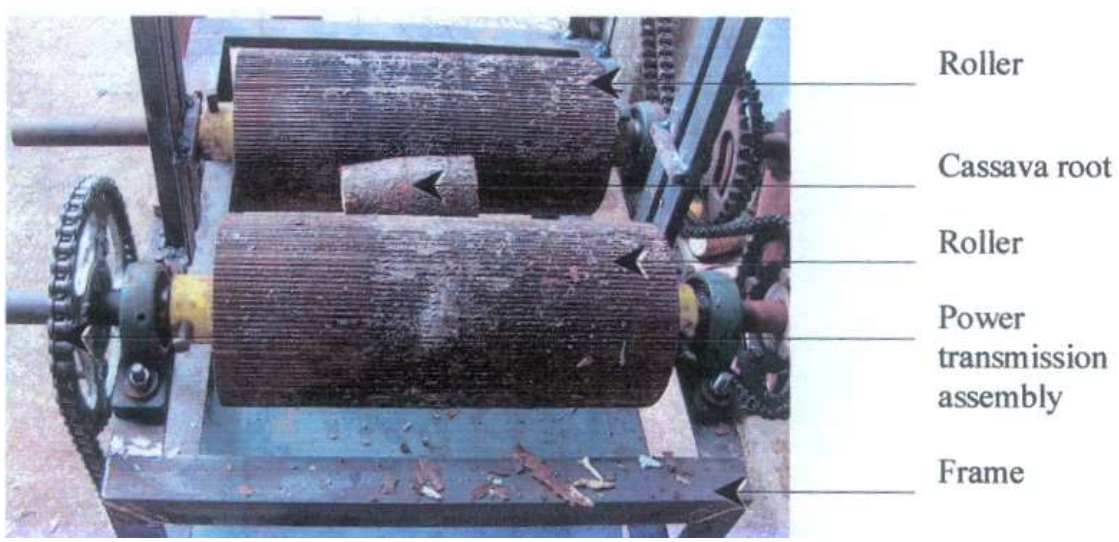

a) Details of the parts

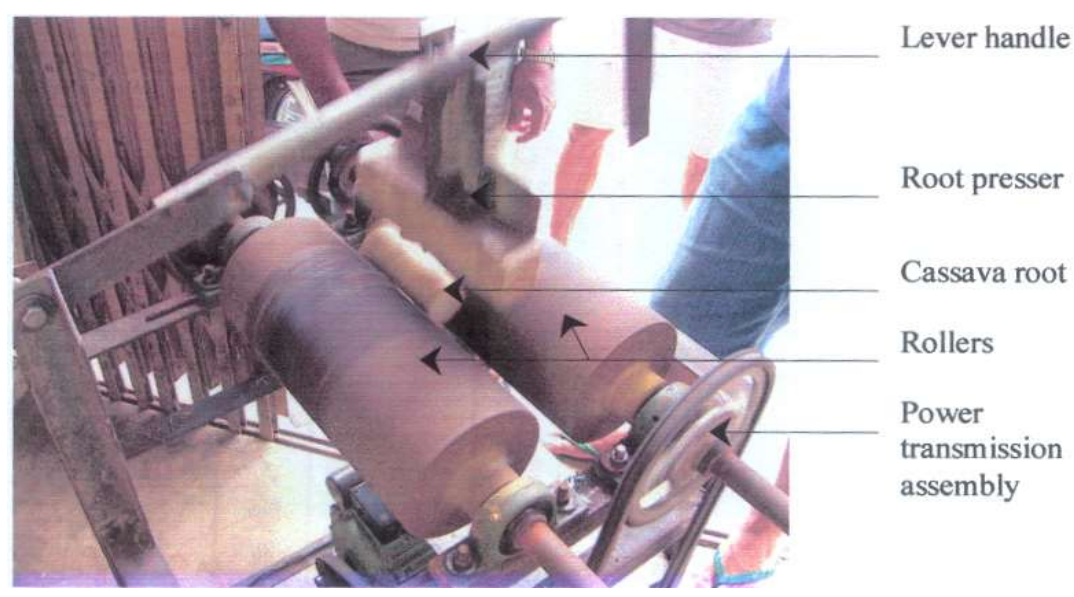

b) During operation

Figure 3. The experimental set-up showing: (a) details of the parts, and (b) during operation 


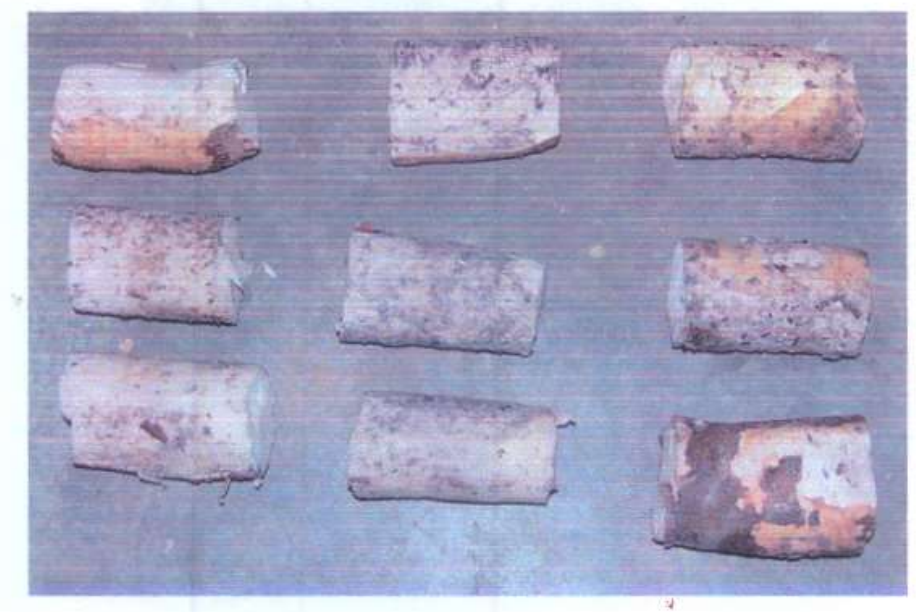

(a) $80 \%$ clearance

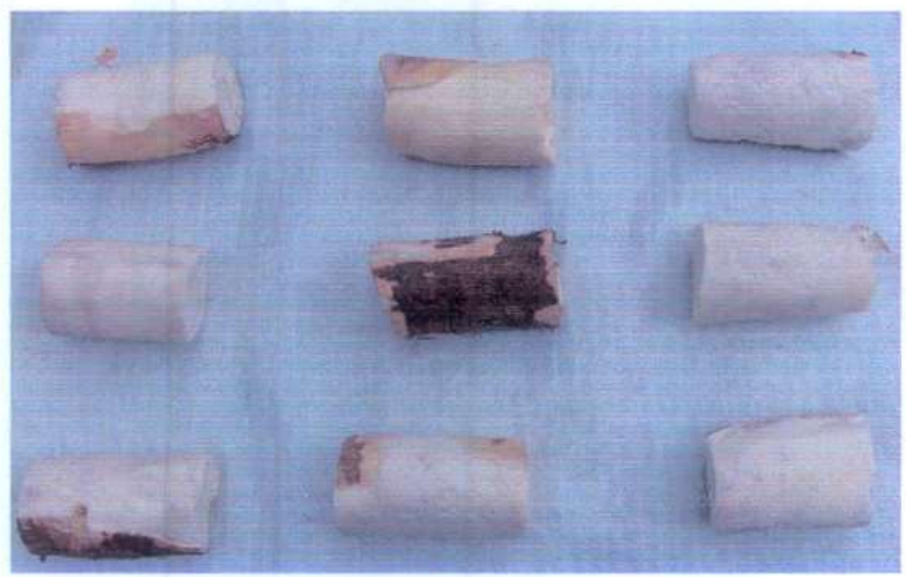

(a) $90 \%$ clearance

Figure 4. Conditions of the peeled roots at (a) $80 \%$ and (b) $90 \%$ clearance distance and at the same direction of rotation of the two rollers 
was transmitted to the speed reducer via the B-29 V-belt, then the reduced speed was transmitted to the rollers through chains and sprockets.

\section{The peeling operation}

The cassava root was fed parallel between the two rollers and pressed manually using the lever presser. The difference in the angular speed of the rollers causes the root to rotate. The rotation of the root made possible the peeling of the entire root by the shearing and abrasive forces of the two rollers and the compression force of the presser. Figure $3 \mathrm{~b}$ shows the peeling operation during the experiment.

\section{The peeling output}

The conditions and the degree of peeling of the cassava roots were thoroughly observed and recorded during and after peeling. Results showed that the amount of peels removed from the root ranges from $10 \%$ to $100 \%$ (Figure 4 and 5). The 100\% removal of peels can be attributed to the uniformity of the cassava roots, clearance distance and direction of rotation of the rollers. It was also observed that there were abrasions on the peeled roots, which can be attributed to the rough surface characteristic of the metal rollers.

\section{Effects of the angular speed combination of the rollers}

Conditions of the cassava roots. Results showed that at any level of the angular speed of the rollers; the peeling of cassava roots occurred. The peeling however varies at each angular speed combinations.

Degree of peeling . At the angular speed combinations of the rollers, the peeling of the cassava roots showed significant variations between the three combinations (Table 1). Results revealed that the highest degree of peeling of about $65 \%$ was attained at $175 \times 405 \mathrm{rpm}$ of the rollers of $50 \mathrm{~mm}$ roots diameter. Furthermore, regardless of the diameter of the roots, the highest mean among the three angular speeds was obtained at the $175 \times 405 \mathrm{rpm}$ of the rollers. Highest degree of peeling was observed when the differential rotation 


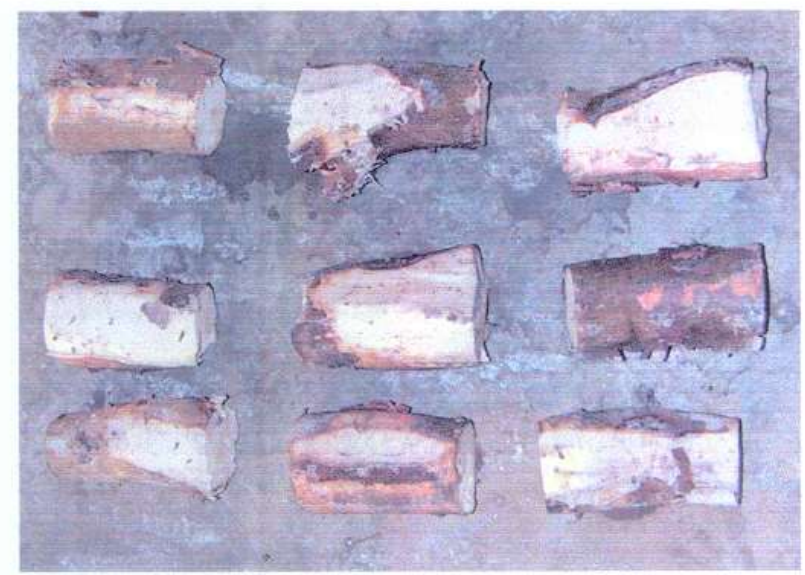

(a) $80 \%$ clearance

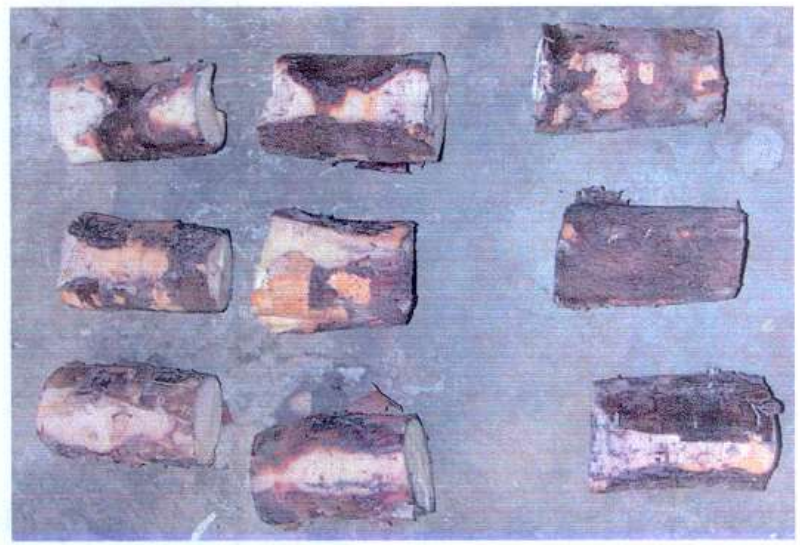

(b) $90 \%$ clearance

Figure 5. Conditions of the peeled cassava roots at (a) $80 \%$ and (b) $90 \%$ clearance at opposite direction of rotation of the two rollers 
Table 1. Mean of the degree of peeling (\%) of the cassava roots at three angular speeds of the rollers

\begin{tabular}{|c|c|c|c|c|c|c|}
\hline \multirow{2}{*}{$\begin{array}{l}\text { Angular } \\
\text { Speed }\end{array}$} & \multirow{2}{*}{$\begin{array}{l}\text { Absolute } \\
\text { differential } \\
\text { speed between } \\
\text { rollers }\end{array}$} & \multicolumn{3}{|c|}{ Size of the roots $(\mathrm{mm})$} & \multirow[t]{2}{*}{ Total } & \multirow[t]{2}{*}{ Mean } \\
\hline & & $3 \overline{5 \pm 5}$ & $50 \pm 5$ & $65 \pm 5$ & & \\
\hline $175 \times 144$ & 31 & 56 & 58 & 53 & 168 & $56 \mathrm{~b}$ \\
\hline $175 \times 180$ & 5 & 19 & 20 & 18 & 56 & $19 \mathrm{c}$ \\
\hline $175 \times 405$ & 220 & 51 & 65 & 61 & 177 & $59 \mathrm{a}$ \\
\hline
\end{tabular}

*Treatment means with common letter are not significantly different at 5\% level based on DMRT

of the rollers was also highest. The variations of the degree of peeling of the cassava roots at percent clearance of the rollers were illustrated further in Figure 7. The figure showed that maximum degree of peeling was attained at the $80 \%$ clearance of the rollers at the $35 \mathrm{~mm}$ diameter of the cassava roots. This condition can be related to the maximum removal of the peels due to the narrow clearance distance between the rollers, in which more friction and pressure are applied than at $90 \%$ clearance.

On the other hand, the minimum value of the degree of peeling of about $26 \%$ was attained at $90 \%$ clearance at $175 \times 180 \mathrm{rpm}$ of the rollers of $35 \mathrm{~mm}$ root's diameter. This minimum value can be attributed to the minimum removal of peels due to the wider clearance distance between rollers, and very low differential angular speed of the two rollers.

\section{Effects of the direction of rotation of the rollers}

Conditions of the cassava roots. Figures 4 and 5 also showed the conditions of the peeled roots subjected to the same and opposite directions of rotation of the rollers. It can be observed that the roots exposed to the same direction of rotation, the peeling of the roots was done all through out the roots' surface. In contrary, the roots exposed to opposite direction of rotation, the peeling of the roots was done only on the roots' surface in contact with the rollers. 
Table 2. Degree of peeling at $80 \%$ and $90 \%$ clearance distances at three angular speeds of the rollers

\begin{tabular}{llllll}
\hline Percent & \multicolumn{3}{l}{ Size of the roots $(\mathrm{mm})$} & Total & Mean \\
\cline { 2 - 4 } Clearance & $35 \pm 5$ & $50 \pm 5$ & $65 \pm 5$ & & \\
\hline $80 \%$ & 58 & 55 & 53 & 166 & $55 \mathrm{a}$ \\
$90 \%$ & 26 & 40 & 35 & 101 & $34 \mathrm{~b}$ \\
\hline
\end{tabular}

*Treatment means with common letter are not significantly different at $5 \%$ level based on DMRT

Table 3. Mean of the degree of peeling (\%) of the cassava roots at the same and opposite directions of rotation of the rollers

\begin{tabular}{llllll}
\hline Treatment & \multicolumn{3}{l}{ Size of the roots $(\mathrm{mm})$} & Total & Mean \\
\cline { 2 - 4 } (Roller Direction) & $35 \pm 5$ & $50 \pm 5$ & $65 \pm 5$ & & \\
\hline The same & 56 & 58 & 53 & 168 & $\begin{array}{l}56 \mathrm{a} \\
\text { Opposite }\end{array}$ \\
\hline
\end{tabular}

*Treatment means with common letter are not significantly different at $5 \%$ level based on DMRT

The maximum peeling attained all through out the root surface at the same direction of rotation of the rollers can be inferred to the rotation of the roots between the rollers, whereas the peeling of the roots' surface in contact with the rollers can only be attributed to the non-rotation of the roots between the rollers.

The rotation of the roots between the rollers can be attributed to the shearing forces exerted by the rollers as it rotates and the compressive force due to the pressure exerted by the root presser, which result to a net compressive and shear force on the root. Thus, the difference in the angular speed of the rollers resulted to the rotation of the roots while the action of the root presser serves as the pusher of the root out from the rollers. Apparently, the non-rotation of the root on the opposite direction of rotation of the rollers 


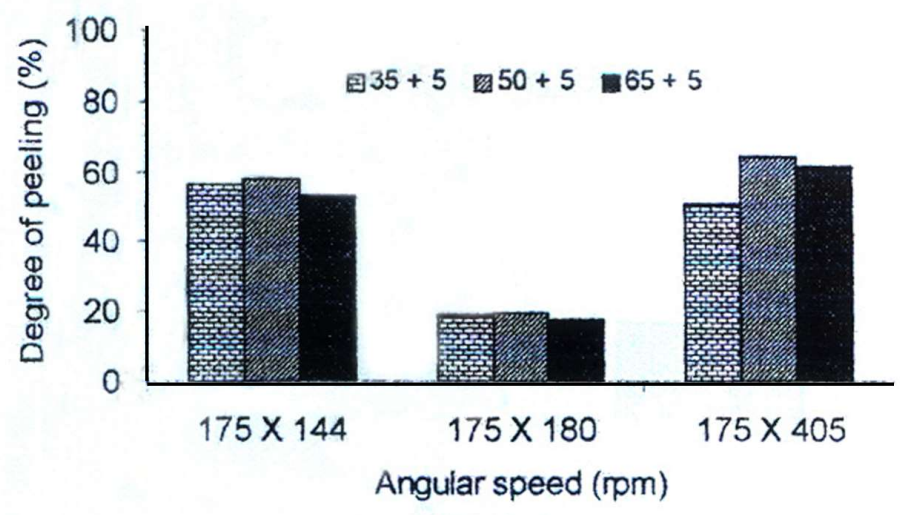

Figure 6. Degree of peeling (\%) of the cassava roots at three angular speeds of the rollers

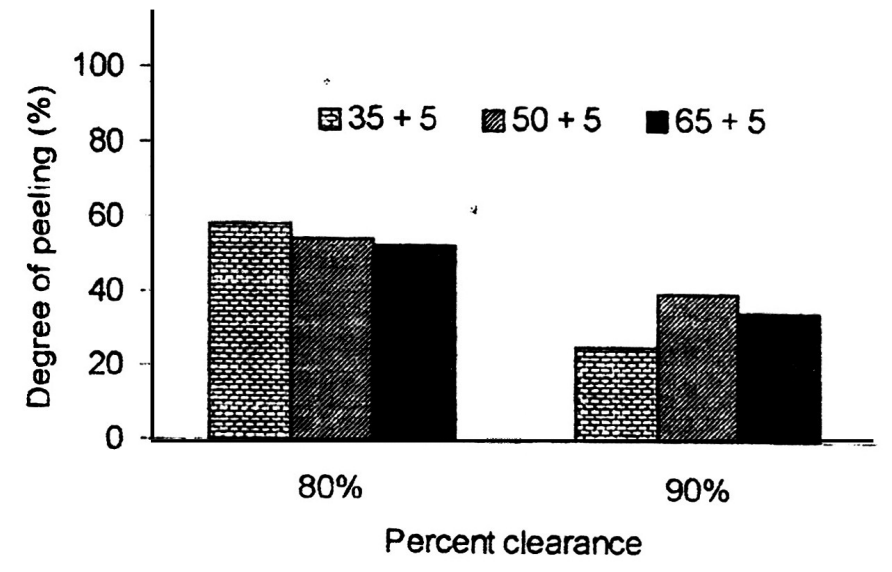

Figure 7. Degree of peeling (\%) of the three sizes of the cassava roots at $80 \%$ and $90 \%$ clearances of the rollers 


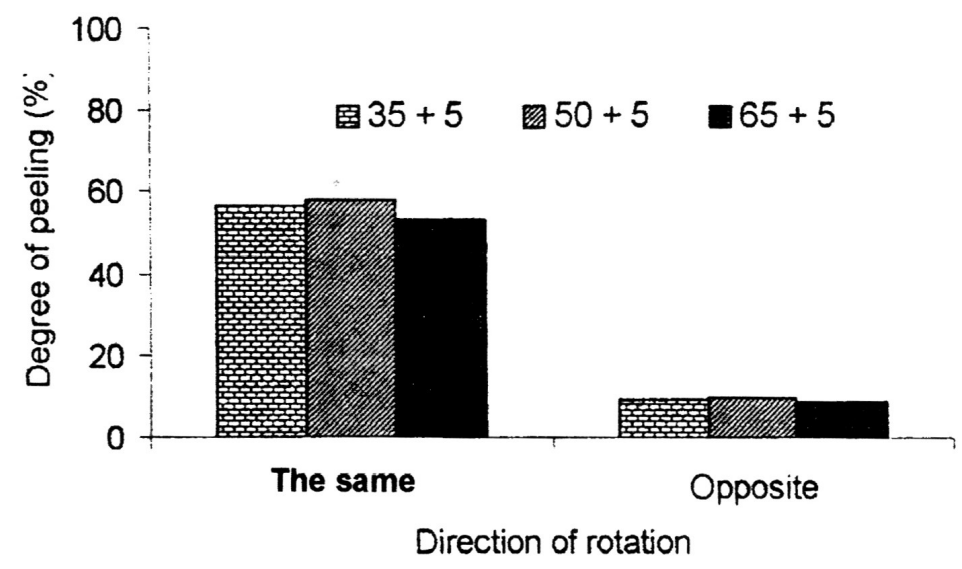

Figure 8. Degree of peeling (\%) of the cassava roots at the same and opposite direction of rotations at three angular speeds of the rollers 
was due to the shearing forces exerted by the rollers as it rotates and the compressive force due to the pressure exerted by the root presser, which result to a net compression force alone on the root (Figure 2b). Thus, the difference in the angular speed of the rollers resulted to the locking-up of the root between the rollers and the grating effects on the roots.

\section{Degree of peeling as affected by direction of roller rotation}

Table 3 shows the degree of peeling of the cassava roots subjected to the same and opposite directions of rotation of the rollers. It shows the significant variation of the degree of peeling at the two directions of rotation of the rollers. Results also showed that of the three angular speed combinations and at two directions of rotations the maximum value of the degree of peeling of about $80 \%$ was attained at $174 \times 144 \mathrm{rpm}$ of the rollers at the same direction while the minimum value of about $13 \%$ was attained at $175 \times 180 \mathrm{rpm}$ of the rollers at opposite direction of rotation. The efficient and maximum peel removal can be attributed to the peeling of the roots in its entire surface due to the rotation of the roots between the rollers. The maximum value observed can be attributed further to the maximum removal of the peels of the cassava roots which was due to the narrow clearance distance between the rollers.

Figure 8 shows the trend of the degree of peeling of the cassava roots subjected to the two direction of rotation. The figure revealed that the maximum degree of peeling was attained at the same direction of rotation of the rollers. This condition can be related to the maximum removal of the peels at the same time direction due to the rotation of the roots between rollers.

On the contrary, the minimum value of the degree of peeling was attained at the opposite direction of rotation of the rollers. This condition was brought about by the peeling of the cassava root on the portion in contact with the rollers due to the non-rotation of the cassava root between the rollers. 


\section{CONCLUSIONS AND RECOMMENDATIONS}

\section{Conclusions}

1. The $175 \times 405 \mathrm{rpm}$ of the rollers attained the maximum degree of peeling amomg the three angular speed combinations.

2. The $90 \%$ clearance distance between rollers resulted to the maximum peeling of the roots with minimum flesh removal compared to the $80 \%$ clearance distance that resulted to the maximum removal of both the flesh and the peels.

3. The same direction of rotation of the rollers was more effective in the entire cassava roots than the opposite roller direciton of the two rollers.

\section{Recommendations}

The following are recommendations that would help in designing the actual mechanical cassava peeler and for further peeling studies:

1. Other surface material of the roller like rubber or other materials should also be evaluated.

2. The effect of the maturity of the cassava roots to peeling efficiency needs to be studied.

\section{LITERATURE CITED}

ANATHARAMAN, M. 1993. Impact of a cassava technology transfers on adoption level by small farmers. Tropical Agriculure. 70(4):359-362.

CAMZALES, V. 1991. Cassava Bread Technology and its Future. FAO. Rome, Italy.

DIOP, A. 1998. Storage and Processing of Roots and Tubers in the Tropics. FAO Publication. Rome, Italy.

GRACE, M. R. 1977. Cassava Processing. FAO Publication. Rome, Italy

NWOKEDI, P. M. 1984. Performance of a Cassava Peeling Machine. Proceedings of the Second Triennial Symposium of the International Society for Tropical Rootcrops - Africa Branch held in Douala, Cameroon, 14-19 August 1983. Tropical Rootcrops: Produciton and Uses in Africa edited by E. R. Terry, E. V. Doku, G. B. Arene and N. M. Mahungu. Ottawa, Ont.: International Development Research, 231, p.:ill. -(IDRC-22le) 
ODIGBOH, E. U. 1976. Mechanical Devices for peeling Cassava Roots. Small-Scale Processing and Storage for Tropical Root Crops edited by Donald L. Plucknett Boulder Col.: Westview Press. 461 p.

ONWUEME, I. C. and CHARLES, W. B. 1994. Tropical root and tuber crops: Production,Perspective and Future Prospects. FAO, Rome. 228 p.

TAN, D. L. S., TROUNG, V. D., and R. P. LAUZON. 1996. Piloting of cassava food processing technology in Hindang and Capoocan, Leyte. Terminal Report, PRCRTC, ViSCA.

UNIDO. 1989. Integrated Cassava Processing. Vienna, 133 p. 